\title{
Spinitectus mariaisabelae n. sp. (Nematoda: Cystidicolidae) from the intestine of the freshwater fish Profundulus punctatus (Cyprinodontiformes) in Mexico
}

\author{
J. M. CASPETA-MANDUJANO ${ }^{1}$, G. CABAÑAS-CARRANZA², G. SALGADO-MALDONADO²
}

\begin{abstract}
${ }^{1}$ Laboratorio de Parasitología de Animales Silvestres, Facultad de Ciencias Biológicas y Centro de Investigaciones Biológicas, Universidad Autónoma del Estado de Morelos. Av. Universidad No. 1001, Col. Chamilpa, C.P. 62210, Cuernavaca, Morelos, México, E-mail: caspeta@buzon.uaem.mx $;{ }^{2}$ Instituto de Biología, Universidad Nacional Autónoma de México, A.P. 70-153, C.P. 04510, Ciudad de México, D.F. México
\end{abstract}

\begin{abstract}
Summary
Spinitectus mariaisabelae n. sp. is described from the intestine of Profundulus punctatus (Günther) (Pisces, Cyprinodontiformes) from the Suchiapa River, State of Chiapas, Mexico. It is characterized largely by the bifurcate distal tip of the larger (left) spicule, spination of the cuticle separated into 4 longitudinal sectors, more or less regularly spaced rings of spines, and by the position of the excretory pore just posterior to the 7 th ring of visible spines. By having the rings of spines divided into 4 sectors, the new species resembles 8 of the 15 American species; however, they can be easily distinguished by the number of spines in the first ring. S. mariaisabelae differs from all its American congeners by possessing a bifurcate distal tip of the left spicule, a unique feature among Spinitectus spp.
\end{abstract}

Key words: Nematoda; Cystidicolidae; Spinitectus; Profundulus punctatus; freshwater fish; Chiapas; Mexico

\section{Introduction}

The nematode genus Spinitectus Fourment, 1883 includes a large number of species described from both freshwater and marine fishes, some amphibians, and one mammal (Boomker, 1993). However, because many species, mainly those from freshwater fishes from the Indian subcontinent, have been poorly described, some authors (e.g., Boomker, 1993; Boomker \& Puylaert, 1994; Petter, 1995; CaspetaMandujano et al., 2000; Caspeta-Mandujano \& Moravec, 2000) prefer to deal with these parasites according to their zoogeographical regions.

At present, 15 species of Spinitectus have been reported from freshwater fishes in the Americas, 10 from North America and 5 from South America. In Mexico, three Spinitectus species have been reported: S. mexicanus (CaspetaMandujano, Moravec et Salgado-Maldonado, 2000), $S$. humbertoi (Caspeta-Mandujano et Moravec, 2000) and $S$. agonostomi, a species originally described from the intes- tine of Agonostomus monticola from the Caribbean region by Moravec and Baruš (1971), has been recently been recorded from Mexican freshwaters (Moravec, 1998; Caspeta-Mandujano, 2005).

Investigations on helminth parasites of freshwater fishes, carried out by the research teams of the Institute of Biology, National Autonomous University of Mexico (UNAM), Centre for Biological Research and Faculty of Biology, Autonomous University of Morelos State, in several rivers of the State of Chiapas, Mexico, revealed a new species of Spinitectus in the intestine of the cyprinodontoid Profundulus punctatus, which is described below.

\section{Materials and Methods}

Fishes were collected by using an electro-fishing machine from the Suchiapa River $\left(16^{\circ} 20^{\prime} 06^{\prime \prime} \mathrm{N}, 9^{\circ} 27^{\prime} 19^{\prime \prime} \mathrm{W}\right)$, near the village of Jesús María Garza, State of Chiapas, Mexico, during February 2004. Nematodes recovered from the intestine were fixed in hot $4 \%$ formaldehyde and cleared with glycerine. Drawings were made with the aid of a Nikon microscope drawing attachment. After examination, the specimens were stored in vials of $70 \%$ ethanol. For scanning electron microscopy (SEM) studies, three specimens were dried by the critical point method. All measurements are given in $\mu \mathrm{m}$ unless otherwise stated. Type specimens have been deposited in the National Helminthological Collection of the Institute of Biology, National Autonomous University of Mexico (UNAM), Mexico City; and in the Parasitological Collection of the Autonomous University of Morelos State, Mexico.

\section{Results}

Family Cystidicolidae Skrjabin, 1946

Spinitectus mariaisabelae n. sp. (Figs 1 -17)

Description 


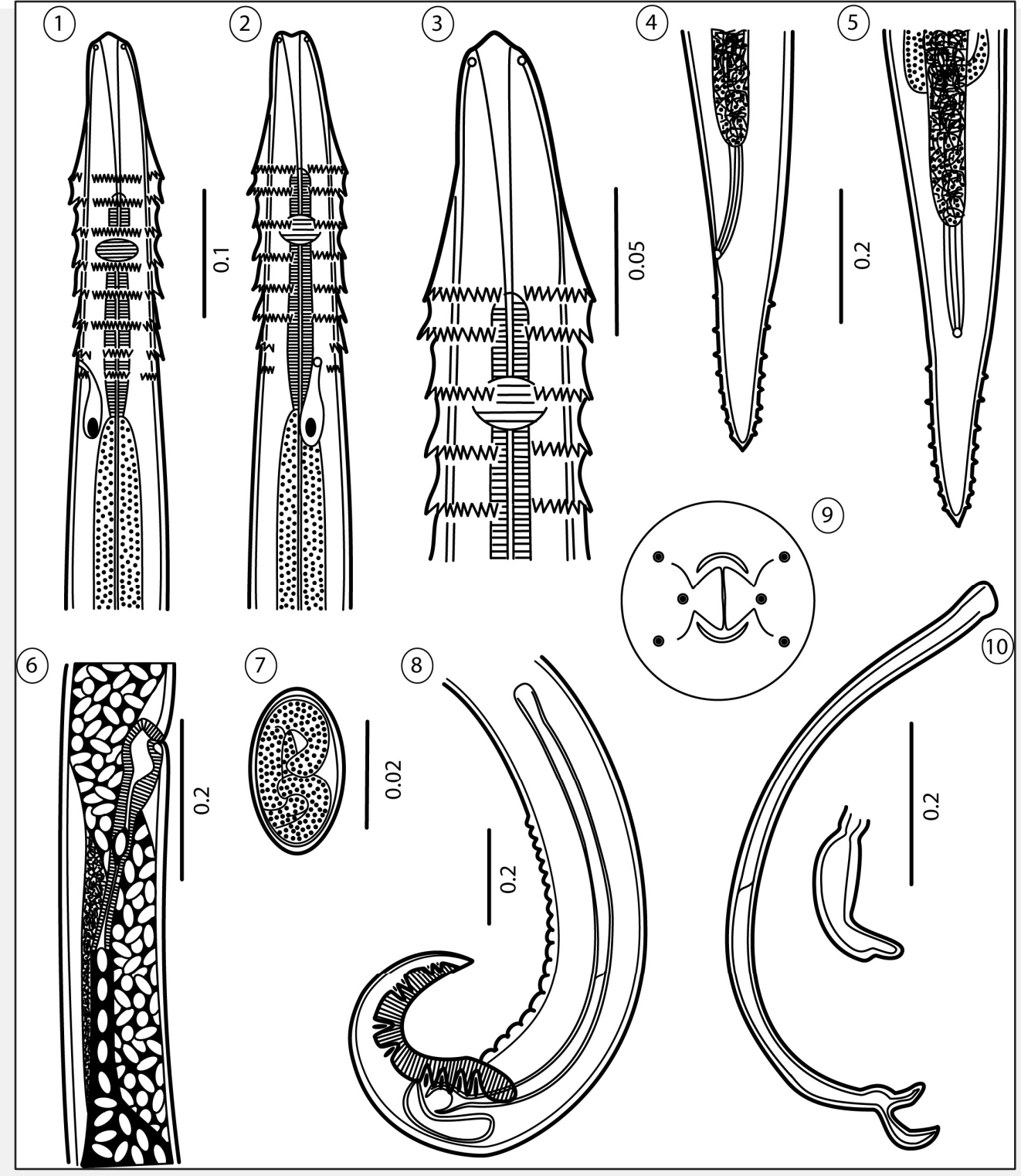

Figs. 1 - 10. Spinitectus mariaisabelae sp. n. 1, 2 - Anterior end of male, lateral and ventral views; 3 - Anterior end of female, larger magnification; 4, 5 - Posterior end of female, lateral and ventral views; 6 - Vulvar region, lateral view; 7 - Egg; 8 - Posterior end of male, lateral view; 9 - Cephalic end, apical view; 10 - Spicules

Medium sized nematodes with rather thick cuticle bearing rings of spines, these being divided at anterior end of body into 4 distinctly-separated dorsolateral and ventrolateral sectors (Figs. 11, 13). First ring usually somewhat anterior to or at level of end of vestibule (stoma) (Figs. 1 - 3). Eight anterior rings of spines well developed; last two rings of spines with a reduced number of spines $(10-12$ in the seventh and $8-10$ in the eighth, Fig. 13); rings more or less regularly spaced (Figs. 1, 2, 13). First ring of spines consisting of $52-60$ spines in males $(13-15$ per sector $)$ and $64-72$ spines in females (Figs 11, 13). Small digitiform deirids situated between first and second ring of spines (Fig. 14). Cephalic end rounded, mouth encircled by pseudolabia, papillae and amphids (Figs 9, 11, 12). Vestibule rather long, its anterior end dilated to form funnelshaped prostom. Excretory pore just posterior to the seventh ring of spines (Figs 1, 2, 15).

Male (15 specimens, holotype in parentheses)

Length of body $6.56-8.28$ (7.67) $\mathrm{mm}$, maximum width $144-184$ (179). Length of vestibule, muscular oesophagus and glandular oesophagus 165 - 195 (195), 299 - 368 (299) and 713 - 851 (851), respectively. Length ratio of muscular to glandular oesophagus 1:2.1 - 2.8 (1:2.8). Distance from anterior extremity: first ring of spines $161-$ 177 (170), deirids 188 - 207 (190), nerve ring 253 - 299 

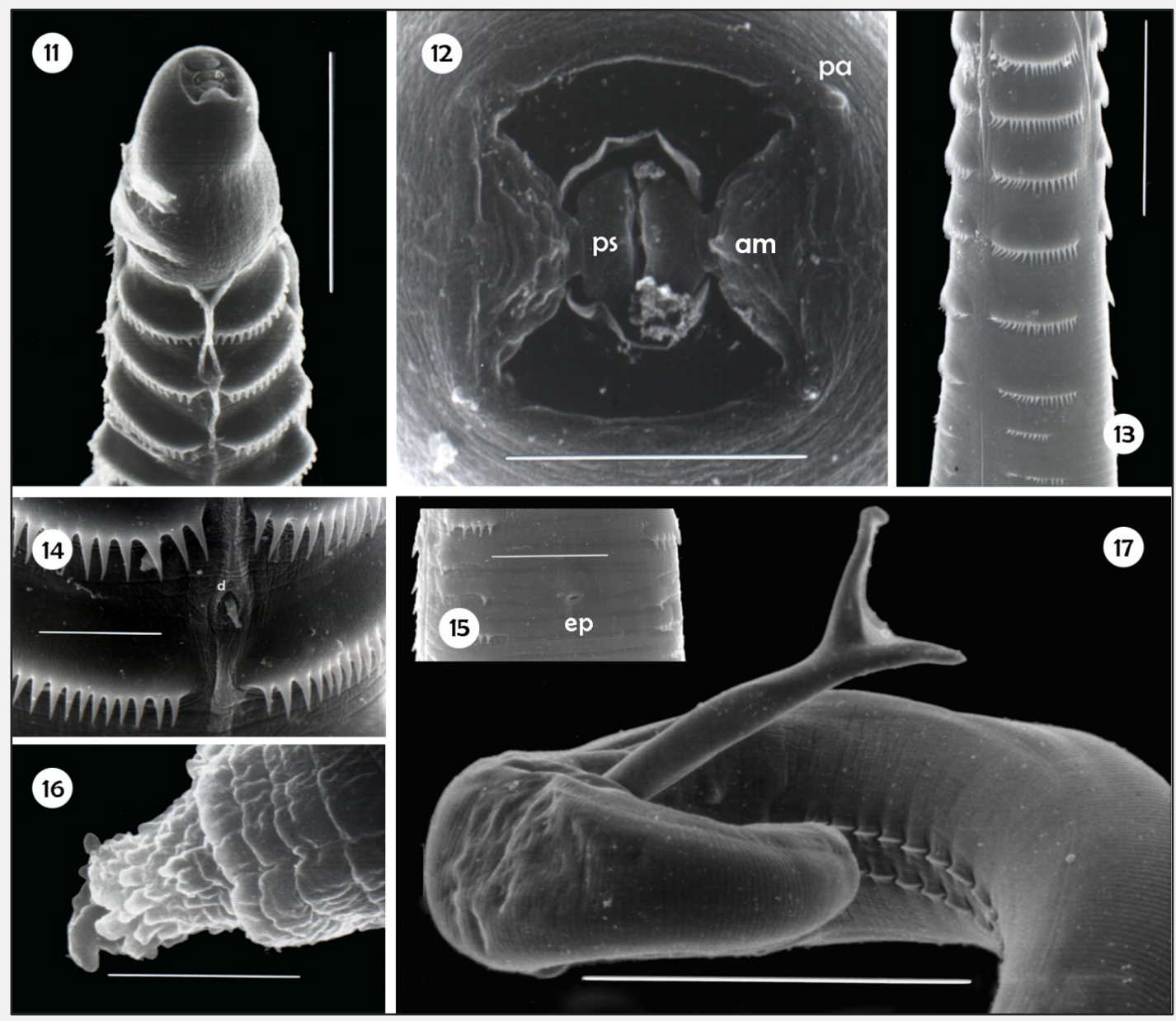

Figs. 11 - 19. Spinitectus mariaisabelae sp. n., scanning electron micrographs. 11 - Anterior end of male, lateral view; 12 - Cephalic end of male, apical view; 13 - Anterior end, rings of spines; 14 - Deirid; 15 - Excretory pore; 16 - Tip of female tail; 17 - Caudal end of male, focused on the left spicule

Abbreviations: $\mathrm{d}$ - deirid; ep - excretory pore; pa - papilla; am - amphid; ps - pseudolabium. Scale bars: Figs. 11, 13, $17=50 \mu \mathrm{m}$;

Figs. $12,14,16=10 \mu \mathrm{m}$; Fig. $15=40 \mu \mathrm{m}$.

(253). Posterior end of body spirally coiled, with narrow subventral caudal alae. Caudal papillae: 4 pairs of pre-anal papillae and 6 pairs of postanal papillae arranged in 3 groups each of 2 pairs (Fig. 8). Area rugosa well developped, formed by 2 longitudinal cuticular ridges (Fig. 17). Larger (left) spicule slender, $1.00-1.10$ (1.08) mm long, with bifurcate distal end; length of its shaft $563-598$ (586), representing $56-59 \%$ of spicule length. Small (right) spicule longer than wide, 195 - 248 (195) long (Figs. 10, 17). Length ratio of spicules 1:4.1 - 5.1 (1:5.1). Tail conical, 230 - 305 (230) long (Fig. 8).

Female (15 gravid specimens, allotype in parentheses): Length 11.82 - 14.58 (11.82) mm, maximum width $276-$ 322 (276). Length of vestibule, muscular oesophagus and glandular oesophagus 195 - 264 (195), 397 - 437 (402) and $1.15-1.54(1.15) \mathrm{mm}$, respectively. Length ratio of muscular to glandular oesophagus 1:2.8 - 3.5 (1:2.8). Distance from anterior extremity: first ring of spines $174-$
220 (174), deirids 195 - 236 (195), nerve ring $264-345$ (264). Vulva pre-equatorial, $4.86-5.98$ (4.86) $\mathrm{mm}$ from anterior extremity (Fig. 6). Fully mature eggs oval, smooth, containing larva; size of eggs $57-59 \times 38-39$ (59 x 39) (Fig. 7). Tail conical, bearing small spines iregularly spaced $264-317$ (317) long (Figs. 4, 5). Tail tip bearing small finger-like processes (Fig. 16).

Type host: Profundulus punctatus (Günther) (Cyprinodontidae, Cyprinodontiformes).

Site of infection: Intestine.

Type locality: Suchiapa River, State of Chiapas, Mexico (types collected in February 2004).

Etymology: The species is named in honour of María Isabel Mandujano Chávez, mother of the first author.

Deposition of types: Holotype, allotype and paratypes in the Institute of Biology, UNAM, in Mexico, City (CNHE 5781, 5782, 5783) and paratypes in the Faculty of Biology, Parasitological Collection of the Universidad Autónoma del Estado de Morelos, Mexico (COPAUAEM N-103). 


\section{Discussion}

A total of 15 species of Spinitectus have been reported as parasites of freshwater fishes in the New World (Spinitectus acipenseri Choudhury et Dick, 1992, S. agonostomi Moravec et Baruš, 1971, S. asperus Travassos, Arti-gas et Pereira, 1928, S. carolini Holl, 1928, S. gracilis Ward et Magath, 1917, S. humbertoi Caspeta-Mandujano et Moravec, 2000, S. macrospinosus Choudhury et Perryman, 2003, S. mexicanus Caspeta-Mandujano, Moravec et Salgado-Maldonado, 2000, S. micracanthus Christian, 1972, S. multipapillatus Setter, 1987; S. osorioi Choudhury et Pérez-Ponce de León, 2001, S. pachyuri Petter, 1984, S. rodolphiheringi Vaz et Pereira, 1934, S. tabascoensis Moravec, García-Magaña et Salgado-Maldonado, 2002, and $S$. yorkei Travassos, Artigas et Pereira, 1928) (see Moravec, 1998; Choudhury \& Perryman, 2003; Caspeta-Mandujano, 2005).

According to Moravec (1979), one of the most stable features in Spinitectus species is the situation of the excretory pore in relation to anterior cuticular spines, but the character of the spination is also used for the separation of species. Of the 15 Spinitectus species reported from freshwaters in the Americas, 8 (S. agonostomi, S. carolini, $S$. humbertoi, S. osorioi, S. macrospinosus, S. mexicanus, $S$. micracanthus and $S$. multipapillatus) have rings of spines markedly divided into 4 sectors. However, the new species can be easily distinguished from them by the number of spines in the first ring $(52-72$ vs. $30-50,20-30,36-$ $38,20-25,28-44,12-20,56-72$ and $15-25)$, and by the conspicuously bifurcate distal tip of the left (larger) spicule. Although the number of spines in the first ring of the new species is rather similar to that of S. micracanthus, they can be easily distinguished by the number of visible rings of spines, being more than 10 rings in the latter species, length of the larger spicule $(1.00-1.10 \mathrm{vs} .305 \mathrm{~mm})$ and by the position of the excretory pore in females (between the $7^{\text {th }}$ and $8^{\text {th }}$ vs $9^{\text {th }}$ and $\left.10^{\text {th }}\right)$.

In that the excretory pore is posterior to the $7^{\text {th }}$ ring of spines, $S$. mariaisabelae resembles $S$. humbertoi; however, the species differ in the number of spines in the first ring, as pointed out above. Moreover, the lengths of the spicules (left $1.00-1.10 \mathrm{~mm}$, right $195-248 \mathrm{~mm}$ vs left $396-412$ $\mathrm{mm}$, right $99-102$ ) and the number of ventral cuticular ridges (2 vs 4 ) are different. The character of the bifurcate distal tip of the larger spicule of $S$. mariaisabelae is a unique feature among all congeneric species.

\section{Acknowledgments}

The authors' thanks are due to M. Reyna and A. Martínez from the UNAM for their help in the field, B. Mendoza Garfias from the UNAM and A. J. Medrano Silva from the UAEM for the technical assistance with the SEM and photographs. Part of this study was supported by the operating grant no. Y026 from the Comisión Nacional para el Conocimiento y Uso de la Biodiversidad (CONABIO).

\section{References}

BoOMKer, J. (1993): Parasites of South African freshwater fish. V. Description of two new species of the genus Spinitectus Fourment, 1883 (Nematoda: Cystidicolidae). Onderstepoort. J. Vet. Res., 60: 139 - 145

BoOMKer, J., PuYlaert, F. A. (1994): Eight new Afrotropical Spinitectus spp. (Nematoda: Cystidicolidae) from freshwater fishes with a key to the members of the genus in the region. Onderstepoort. J. Vet. Res., 61: 127 - 142

Caspeta-Mandujano, J. M. (2005): Nematode Parasites of Freshwater Fish of Mexico: Key to Species, Description and Distribution. Universidad Autónoma del Estado de Morelos, Cuernavaca, Morelos, Mexico, 175 pp.

Caspeta-Mandujano, J. M., Moravec, F. (2000): Two new intestinal nematodes of Profundulus labialis (Pises, Cyprinodontidae) from fresh waters in Mexico. Acta $\mathrm{Pa}$ rasitol., 45: 332 - 339

Caspeta-Mandujano, J. M., Moravec, F., SalgadoMALDONADO, G. (2000): Spinitectus mexicanus n. sp. (Nematoda: Cystidicolidae) from the intestine of the freshwater fish Heterandria bimaculata in Mexico. J. Parasitol., 86: $83-88$

Choudhury, A., Perryman, B. J. (2003): Spinitectus macrospinosus n. sp. (Nematoda: Cystidicolidae) from the channel catfish Ictalurus punctatus in Southern Manitoba and its distribution in other Ictalurus spp. J. Parasitol., 89: $782-791$

MoRAVEC, F. (1998): Nematodes of Freshwater Fishes of the Neotropical Region. Academia, Prague, 464 pp.

MoraVEC, F. (1979): Redescription of the nematode Spinitectus inermis parasitic in eels, Anguilla anguilla, of Europe. Acta Soc. Zool. Bohemoslov., 43: 35 - 42

MoraVec, F., BARUŠ, V. (1971): Studies on parasitic worms from Cuban fishes. Acta Soc. Zool. Bohemoslov., 35: $56-74$

PetTer, A. J. (1995): Nematodes de poissons du Paraguay. VIII. Habronematoidea, Dracunculoidea et Ascaridoidea. Rev. Suisse Zool., 102: 89 - 102

ACCEPTED APRIL 28, 2007

RECEIVED JANUARY 7, 2007 